\title{
About Palliative Care
}

\section{Magali Roseira Boemer ${ }^{1}$}

Much has been written about the humanization of care and, particularly, about the humanization of patient care towards death. From a first perspective, it can appear to be a specific issue; however, humanized care, in terms of a person's process of finitude, is intrinsically associated with providing care as of primary care. Hence, terminal patient care is more (or less) humanized depending on how that care has been delivered since that moment. In this sense, that patient can be a person with no chance of treatment, who is more fragile or stronger depending on the humanization aspect of the care they received.

Patients with advanced often terminal diseases are a reality in hospitals, posing serious difficulties for the administrators, health professionals, relatives, and for patients themselves. There are many problems and challenges to be overcome, including the lack of human resources to deal with and meet the patients' and their family's demands; the lack of a national network to manage long-term continuous medical interventions which harm an approach that would relieve patient suffering; the inexistence of a domiciliary support network; and the fact that end-of-life care are not a priority for public health administrators.

Palliative care and hospice care propose a transformation in the form that care is provided to people with serious terminal diseases, changing the paradigm of cure to that of care.

The referred form of care currently exists in 116 countries, with United States being the country with the greatest number of hospices. Despite the difficulties to include this movement in the Brazilian Public Health System, there is no doubt about the global interest in the issue.

Hence, palliative care is a proposal of care for people facing death and covers relevant aspects, pertinent to the many dimensions of the person's existence. Palliative care covers a broad interdisciplinary program for patients with advanced diseases, aiming at relieving the patients' most stressful symptoms and offering them a protective mantle (palliative derives from the Latin pallium: matle, cover).

From that perspective, palliative care should not be considered an alternative for ineffective curative treatment; rather, it should be seen as a group of care actions provided to the patient, as of the commencement of treatment, thus constituting a specialized approach to help that person live better, improving every and any treatment that promotes quality of life until the moment of death.

The Brazilian Health Ministry has stated its concern regarding the growing need for palliative care and pain management. Based on the health problems in Brazil, it has passed Ordinance GM/MS no 19, of January 3rd 2002, instituting the National Program for Pain Management and Palliative Care, which made it possible for new debates regarding this issue and professional training to take place. In addition, the program reviews the conducts pertinent to the care for patients with chronicdegenerative diseases or terminal patients and their relatives. There have been many national initiatives, and studies have warned about the need to implement palliative care in all health care levels.

Yet, the gap in the education of health professionals, in regards to this issue, has been an obstacle for the care to patients experiencing their terminality.

In Brazil, there have been some initiatives in the sense of implementing this care philosophy; however, there is still much to be accomplished in order to implement this therapeutic approach. We must deal with the difficult access to health care services, the flaws of health policy guidelines, the deficient education of health professionals and, mainly, the lack of information to patients along with the need to manage these patients' pain, relieve the symptoms, and promote a better quality of life for them. Technological advancement and the consequent early detection of diseases has helped some professionals to direct their views towards this issue and, in this way, they have improved their knowledge regarding this approach, incorporating the concept of care and not only cure.

In 1997, the Brazilian Association for Palliative Care (Associação Brasileira de Cuidados Paliativos - ABCP) was created, and has promoted several international events since then. One year later, the ABCP performed a survey of the existing services for pain management and palliative care across the nation, and found there were 30 institutions with those characteristics; 20 were in the Brazilian Southeast, six in the South, one in the Central-West, one in the North, and two in the Northeast.

The palliative approach is the only real option for most patients with chronic-degenerative diseases, and this health care service can only count on a part of the financial resources available, since a great part of the budget is designed for curative treatments. In this sense, it is necessary to recognize that this often neglected thematic concerns a public health issue. Factors of great importance to make palliate care feasible include creating matrix teams to support and train health professionals, providing medication for managing disease signs and symptoms, and creating laws to protect health professionals, patients and their relatives.

Despite the many obstacles for implementing palliative care, there are currently a high number of studies on this thematic. The questions emerge from health professionals providing direct care to these people, which have resulted in the growing number of events, scientific conferences, and publications. In 2008, several seminars, congresses, lectures and symposiums addressed themes such as pain relief, humanization, the use of opioid drugs, and the global inclusion of palliative care.

${ }^{1}$ Retired Associate Professor of the Department of General and Specialized Nursing at Ribeirão Preto College of Nursing at University of São Paulo. Ribeirão Preto, SP, Brazil. boemerval@gmail.com 
According to the Brazilian Ministry of Health, in order to provide palliative care, there is a need for a multiprofessional team composed of, at least, physicians, nurses, nutritionists, psychologists, social workers, physiotherapists, and occupational therapists working from an interdisciplinary perspective. These professionals must receive equal recognition and appreciation and work together so as to contemplate the patients' and their family's autonomy.

In this sense, it is necessary to think about including nursing in palliative care, considering the interdisciplinarity, since care is inherent to the profession since its modern conception, as proposed by Florence Nightingale. Therefore, considering this principle, nurses can help the patients who are facing death, with the preservation of their dignity as the guideline of health care.

Regarding this preservation, special attention should be given to pain control and management, the hygiene of patients and their clothing and environment, creating attachments, sharing decisions with patients, exercising their autonomy, flexibility (concessions, breaches) versus rigidity, bureaucracy, meeting the patient's small-big desires, honest answers, and consideration regarding the limits of professionals and caregivers.

For nurses, there is also the issue regarding the techniques, which can receive another meaning. There is no doubt that they are skills of the nursing work process and are an essential content in the process of nurse education. However, they must be developed in a way that health care is not delivered to the patient as a fragmented object.

It is impossible to separate, when performing a technical procedure, the affective and existential aspects of the person being cared for. If this is respected, the relationship with the patient becomes stronger.

The specificity of care and the particular condition of severely ill patients usually make nurses see themselves in difficult situations that involve conflicts between the patient and the medical team. The bureaucratic structure of the institutions usually assigns physicians with the power. However, despite the fact that nurses have a peripheral power, they can represent a platform of privileged mediation between patients and the medical power. Proximity is what confers nurses this power; it makes it possible for them to defend the patient, exert certain subversion, encouraging the patient to fight for his or her autonomy.

Furthermore, this power allows nurses to make norms and routines more flexible, to break some rules that should be more logical, and open breaches thus making the institution more humanized for the patients.

It is common, in the everyday work context, to see these patients facing difficult decision-making moments. One should recall that the decision-making process is not linear. It takes place in circles and, thus, these moments are filled with conflicts, ambiguities, and contradictions, because they are humans.

If health professionals let go of the old and abolished concept that they should not become emotionally evolved, they will be able to use their subjectivities to capture that of the patient, they will be able to establish intersubjectivities that facilitate nursing care and will make, even if informally, the essential marks of the philosophy of palliative care.

In this way, as a nurse, I see nursing, in its essence, as a human science, since it addresses humans. Either regarding planning, managing, or the direct act of care, humans will always be present.

Patients expect a human engagement from the professionals that care for them; they expect attachment, a personal availability to be-with and, in this sense, to invest in the patient relationship requires establishing strategies that humanize health care. However, those strategies go beyond the ontic instance only when patients are seen as unique individuals; otherwise they become additional techniques and norms.

Nursing care needs to be founded on the following question - what human being does this care contemplate? The object of the manifestation of science or that which, while a being-in-the-world, is always a will-become, an unfinished project? 